\title{
1 Byproducts as a Source of Novel Ingredients in Dairy Foods
}

2 M. Iriondo-DeHond ${ }^{\mathrm{ab}}$, E. Miguel ${ }^{\mathrm{b}}$, M.D. del Castillo ${ }^{\mathrm{a}}$

3 a Instituto de Investigación en Ciencias de la Alimentación (CIAL) (CSIC-UAM), C/ Nicolás

4 Cabrera, 9, Campus de la Universidad Autónoma de Madrid, 28049 Madrid, Spain.

5 b Instituto Madrileño de Investigación y Desarrollo Rural, Agrario y Alimentario 6 (IMIDRA), N-II km 38,200, 28800 Alcalá de Henares, Spain.

$7 \quad *$ Corresponding author. E-mail: mdolores.delcastillo@csic.es 


\section{CONTACT INFORMATION:}

10 Maite Iriondo-DeHond

11 Address: Instituto Madrileño de Investigación y Desarrollo Rural, Agrario y Alimentario

12 (IMIDRA), N-II km 38,200, 28800 Alcalá de Henares, Spain.

13 Instituto de Investigación en Ciencias de la Alimentación (CIAL) (CSIC-UAM), C/ Nicolás

14 Cabrera, 9, Campus de la Universidad Autónoma de Madrid, 28049 Madrid, Spain.

15 Email: Maite.iriondo@madrid.org

16 Phone: +34918879382

17 Eugenio Miguel

18 Address: Instituto Madrileño de Investigación y Desarrollo Rural, Agrario y Alimentario

19 (IMIDRA), N-II km 38,200, 28800 Alcalá de Henares, Spain.

20 Email: eugenio.miguel@madrid.org

21 Phone: +34918879410

22 Ma Dolores del Castillo

23 Address: Instituto de Investigación en Ciencias de la Alimentación (CIAL) (CSIC-UAM), C/

24 Nicolás Cabrera, 9, Campus de la Universidad Autónoma de Madrid, 28049 Madrid, 25 Spain.

26 Email: mdolores.delcastillo@csic.es

27 Phone: +34 910017900 ext 953 


\section{Keywords}

29 byproducts, dairy products, functional foods, sustainability, health

\section{Synopsis}

31 The food industry generates a large amount of food wastes and byproducts along the

32 food chain. These fractions are excellent sources of bioactive compounds and nutrients

33 with a high potential for valorization as novel food ingredients. In this chapter, the

34 applications of byproducts in the development of sustainable and novel dairy foods 35 were revised.

\section{Abstract}

37 Food losses represent a waste of resources used in production, in addition to the loss of

38 the economic value of the food produced. The valorization of food wastes and

39 byproducts has become a major subject of research to improve the sustainability of the

40 food chain. Food byproducts are excellent sources of bioactive compounds and

41 nutrients with a high potential for application as novel food ingredients. In this chapter

42 we revised the latest data on food loss generation, the group of byproducts mostly used

43 as food ingredients in dairy product development, and their function in the dairy matrix.

44 We also address the challenges associated with the sensory properties of the products

45 developed including ingredients obtained from byproducts, and consumers attitude

46 towards these new sustainable and novel dairy foods. 


\section{Introduction}

48 The large amounts of byproducts generated in the food industry, together with the need of innovation in the dairy sector, has led food researchers to look for new alternatives to valorize these food side streams and develop novel dairy foods.

51 The potential of the valorization of these agro-industrial food wastes and byproducts is currently supported by the extensive information available on their content of healthy promoting phytochemicals (Teixeira et al., 2014). This has led to the rise in popularity of various health promoting functional foods, including a wide range of products within the dairy sector. Yogurts are particularly trendy among functional foods because they are one of the most preferred foods by consumers as carriers for bioactive ingredients (Ares,

57 Giménez and Deliza, 2010).

The development of novel food and/or functional food products is increasingly challenging, as it has to fulfill the consumer's expectations for products that are simultaneously palatable and healthy (Granato et al., 2010a). Compared to conventional foods, the development of functional components and technological solutions can be demanding and expensive, and it needs of a tight strategy between research and business. All this, in a context where functional food markets are continuously changing (Menrad, 2003; Urala and Lähteenmäki, 2007). In this era where people are shifting from synthetic to natural and newer ways of healthy living, using new sources of bioactive compounds, as food byproducts, are being explored (Sharma et al., 2015). Sustainability presents both a challenge and opportunity to the dairy sector. An opportunity, because the possibility of utilization of food processing byproducts for bioactive compound and nutrient extraction has created 
enormous scope for waste reduction and indirect income generation (Espírito Santo et al., 2012a). However, the challenge is to render the concept of sustainable functional foods into a marketable product that can be accepted by consumers. Granato et al., (2010b) described that the acceptance to a specific functional ingredient or a functional food is linked to the consumer's knowledge of the health effects of specific ingredients. Therefore, more efforts need to be done to influence consumer demand patterns and make sustainability, together with health, one of the main drivers in food consumption.

\section{Byproducts Used as Novel Ingredients in Dairy Foods.}

Food waste was defined by FAO in 1981 as the wholesome edible material intended for human consumption, arising at any point in the food chain system that is instead discarded, lost, degraded or consumed by pests.

The latest Food Balance Sheets (FA0, 2017) indicated that fruits and vegetables presented the highest values of food waste along the food chain compared to the rest of the commodity groups: cereals, roots and tubers, oilseeds and pulses, meat, fish and seafood, and dairy products. In industrialized regions, losses were generated throughout the food chain, especially due to post-harvest fruit and vegetable grading caused by quality standards set by retailers, but also at the consumer level, with $15-30 \%$ of the purchases being discarded (FAO, 2011).

Considering the number of studies published from 2000 to $2017,86.2 \%$ of them used byproducts from plant materials for the development of innovative health promoting dairy products (Figure 1). Plant byproducts include a wide range of food matrixes which are sources of functional ingredients like antioxidants and dietary fibers (Galanakis, 
2011). Hence, they enable wide range of potential functions and technological uses. In the development of novel dairy foods, $60.4 \%$ of the studies used byproducts from fruit $(48.3 \%)$ or vegetables (12.1\%), followed by the application of winery byproducts (19\%).

Byproducts from meat, fish and seafood contain high amounts of protein, which may be less necessary in dairy foods as they already contain this compound in their matrix. However, when protein has been needed, it has been mostly obtained from cheese whey, which is a saccharide and protein rich dairy waste generated during cheese production (Pasotti et al., 2017).

\section{Applications as Ingredients in Dairy Foods}

102 During the last years there have been different approaches in the applications of food byproducts in dairy foods. Most studies have focused on using plant byproducts for the extraction of functional ingredients such as polyphenols, dietary fiber and others.

\section{Polyphenols}

106 Polyphenols are secondary metabolites that are synthesized during normal plant development and in response to stress conditions (Naczk and Shahidi, 2004). Plant phenolics include phenolic acid and its derivatives, flavonoids, lignans and stilbenes (Costa et al., 2017). Although phenolic compounds are not considered nutrients, several biological and pharmacological activities have been attributed to dietary polyphenols, including antioxidant, anti-allergic, anti-inflammatory, anti-viral, anti-microbial and anticarcinogenic effects (Bahadoran, Mirmiran and Azizi, 2013). These properties play a relevant role in the prevention of several major chronic diseases associated with 
114 oxidative stress, such as cardiovascular diseases, cancers, type II diabetes,

115 neurodegenerative diseases or osteoporosis (Scalbert et al., 2005). In this sense, the

116 health-protecting capacity of plant phenolics has become of great interest for

117 researchers, the food industry and consumers.

118 Although phenolic compounds are ubiquitous in plants, they are not uniformly

119 distributed at the tissue, cellular and subcellular levels (Naczk and Shahidi, 2004). Peels,

120 husks, hulls, pods and bran are major processing byproducts of the fruit, vegetable and

121 cereal industry that are considered sources of polyphenols.

122 Product development using byproducts as a source of polyphenols has mostly been

123 carried out in yogurt and fermented milks (Table 1). Namely, winemaking byproducts

124 have been used as the main source of polyphenols, including different flours and

125 extracts from grape pomace and other selective fractions, such as grape skins and seeds.

126 This could be justified both by the fact that black grapes stand among the richest dietary

127 sources of polyphenols (Dimitrios, 2006; Pérez-Jiménez et al., 2010) and by the high

128 amount of grape losses generated during processing and conversion into wine, storage

129 and transportation, which reached 3637 thousand tons in 2013 (FA0, 2017).

131 Addition of polyphenols in dairy foods other than yogurt and fermented milks has 132 received less attention. Wine pomace byproducts have been the major source of 133 polyphenols in the development of cheese (Shan et al., 2011; Felix da Silva et al., 2015; 134 Marchiani et al., 2015). On the other hand, lycopene from tomato peels was used to 135 improve oxidative stability during storage of ice-cream and butter (Kaur et al., 2011; 136 Rizk, El-Kady and El-Bialy, 2014; Abid et al., 2017). 
137 Frumento et al. (2013), Tseng and Zhao (2013) and Marchiani et al. (2016) used doses

138 ranging from $1 \%$ to $6 \%$ of wine pomace flours in fermented milk and yogurt 139 development. However, more recent studies have switched towards using extracts from 140 wine pomace, as lower amounts of the concentrated extracts were needed to achieve 141 significant polyphenol levels (Ersöz et al., 2011; Chouchouli et al., 2013; Aliakbarian et 142 al., 2015; dos Santos et al., 2017). Other byproducts from fruits, nuts, vegetables and 143 cereals were also used as sources of polyphenols for the development of fermented milk and yogurt. Byproducts included pomegranate seeds and peels, almond peels, hazelnut skins, olive pomace and rice bran (Ersöz et al., 2011; El-Said et al., 2014; Bertolino et al., 146 2015; Ozcan et al., 2016; Demirci et al., 2017; Vital et al., 2017).

147 In foods, polyphenols may contribute to the bitterness, astringency, color, flavor and 148 odor of the products (Shahidi and Naczk, 2006). Polyphenols are associated with the 149 precipitation of salivary glycoproteins and mucopolysaccharides onto the tongue, 150 resulting in roughness and dryness on the palate (Haslam and Lilley, 1988). Therefore, it

151 is necessary to achieve a compromise between functional properties and sensory acceptance. Marchiani et al. (2016) reported a significant decrease in the overall acceptance of yogurts with $6 \%$ added polyphenols from grape skin flours. Similarly, Tseng and Zhao (2013) reported significantly lower overall acceptance scores in yogurts with $1 \%$ and $2 \%$ grape pomace powders. Moreover, yogurts with $2 \%$ grape pomace powders were significantly less accepted in terms of yogurt texture and consistency than those with $1 \%$ of grape pomace powders. The inverse relation between polyphenol dosage and consumer acceptance in dairy products has been widely described (Tseng and Zhao, 2013; Bertolino et al., 2015; Marchiani et al., 2015; Karnopp et al., 2017). In this sense, several researchers have opted to include other ingredients that could mask 
161 the negative sensory effects of polyphenols. In yogurt and fermented milk fortification

162 with wine pomace byproducts, the best acceptance scores were obtained when adding 163 the polyphenols in combination with sucrose (5\%), oligofructose ( $0.5 \%$ to $0.667 \%)$ or 164 grape juice (0.167\% to 0.5\% and 15\%) (dos Santos et al., 2017; Karnopp et al., 2017).

\section{Dietary fibers}

166 Plant derived byproducts, such as seed, skins, pods, peels, pomace, hulls, husks, cores,

167 stores, etc., are known sources of bioactive compounds and nutrients including dietary 168 fiber (McKee and Latner, 2000; Sharma et al., 2015), whose caloric value has been 169 estimated at $2 \mathrm{kcal}$ per g (FDA, 2018). The European Food Safety Authority, (2010) 170 defined dietary fiber as non-digestible carbohydrates, including non-starch

171 polysaccharides, resistant starch and oligosaccharides, and lignin. A terminology often encountered is the classification of dietary fiber into "soluble" and "insoluble" (Álvarez

173 and González, 2006). Therefore, the physicochemical properties of the different dietary

174 fibers can be determinant when selecting their applications.

175 The European Food Safety Authority confirmed that there is evidence of health benefits associated with consumption of diets rich in fiber-containing foods at dietary intakes

177 greater than $25 \mathrm{~g}$ per day. Health benefits have been related to reduced risk of coronary 178 heart disease, intestinal disorders, type 2 diabetes and improved weight maintenance 179 (Peters et al., 2003; Pereira et al., 2004; Lindström et al., 2006).

180 Product innovations have been focused on increasing the fiber content of dairy foods to 181 facilitate consumers achieving the daily recommended intake of dietary fiber. Also, as a 182 marketing strategy with the final aim of adding a nutritional claim in the food package. 
184

185

186

187

188

189

190

191

192

193

194

195

196

197

198

199

200

201

202

203

204

205

206

the nutritional claim "source of fiber" or "high in fiber" may only be made when the product contains at least $3 \%$ or $6 \%$ dietary fiber, respectively. Bearing this in mind, several researchers have used dietary fiber concentrations ranging from $2.5 \%$ to $10 \%$ to evaluate its feasibility as an ingredient in dairy products (Table 2). This is because an increase in concentrations of dietary fiber in foods can lead to changes in the resultant nutritional, textural, rheological, and sensory properties of the developed products (Guillon and Champ, 2000).

Product development using byproducts as a source of dietary fiber has mostly been carried out in yogurt and fermented milks. As observed in Table 2, available studies have used a wide variety of plant origin sources derived from fruit and vegetable industry byproducts. Water soluble soybean polysaccharides from okara, which is the byproduct of tofu, soymilk and soybean protein isolate, were used in the development of icecream, pudding and a milk-based beverage (Chen et al., 2010). From the initial concentration ranges tested of fiber addition ( $3 \%$ to $10 \%$ in the milk beverage, $4 \%$ to $8 \%$ in pudding, and $1 \%$ to $4 \%$ in ice-cream), optimal sensory acceptance was achieved at $4 \%$ fiber addition in the milk beverages and pudding, and at $2 \%$ fiber addition in ice-cream. This was due to texture modifications in the dairy matrixes, as consumers considered fiber fortified dairy foods too thick when evaluated using Just About Right (JAR) scales. In fermented milks and yogurts, fiber from apple pomace (3\% to $10 \%$ ), date byproducts $(1.5 \%$ to $4.5 \%)$ and hazelnut skins (3\% to $6 \%)$ were used in the development of dietary fiber enriched foods (Hashim, Khalil and Afifi, 2009; Bertolino et al., 2015; Issar, Sharma and Gupta, 2016). In these cases, optimal sensory acceptance of the products was 
obtained at 3\% fiber addition from hazelnut skins and dates, and 5\% fiber addition from apple pomace.

Addition of byproducts containing dietary fibers has also been applied in dairy foods with technological purposes, such as fat replacers, probiotic carriers or texture agents.

211 Dietary fiber from orange byproducts was used to develop lemon ice-cream with a fat

212 content reduction of 50\% (Crizel et al., 2014), and as fat replacers in low-fat yogurt (Yi et al., 2014). The authors showed that reducing particle size of the orange dietary fibers by micronization increased their water and oil holding capacities, which are also important functional properties in relation with the facilitation of digestion and absorption of nutrients in the body.

217 Apple, banana and passion fruit byproduct fibers were used to preserve viability of

218 Lactobacillus acidophilus and Bifidobacterium animals subsp. lactis strains in yogurt during the shelf life of the products (Espírito Santo et al., 2012a). Namely, apple and banana byproduct fibers helped preserve probiotic viability up to 4 weeks of cold storage. In addition to the probiotic viability evaluation, the authors observed that the

222 probiotic strains were able to modify the fatty acid composition of milk during its fermentation to obtain yogurt. In the presence of the probiotic strains studied, the

224 addition of banana fiber significantly increased $\alpha$-linoleic acid content, whereas passion fruit fiber promoted the increase of conjugated linoleic acids in probiotic yogurts. As a result, the fatty acid profile of yogurts was improved due to a synergistic effect between

227 the type of fiber used and its fermentation by the probiotic strain. The application of 228 dietary fiber from fruit byproducts was shown to be a more cost-effective and 
commercial soluble fiber that are normally used to improve the fatty acid profile of yogurts (Espírito Santo et al., 2012a).

232 Texture and rheological parameters of yogurts were analyzed when adding $1 \%$ of 233 pineapple peel powders (Sah et al., 2016). Yogurt firmness and storage modulus decreased, and the syneresis level was similar to prebiotic-inulin yogurts. The color and textural properties of butter fortified with fibers from vegetal and fruit wastes (stone pear, celery roots and leaves, spinach, orange albedo) was evaluated by Göksel Saraç and Dogan, (2016). The type and dose (from 3\% to 5\%) of dietary fiber used changed the hardness and the spreadability rate, color and sensory acceptance of the butters. Results showed that butter produced with stone pear dietary fiber (3\%) was the most preferred.

240 The influence of different doses (0.6\% to $1 \%)$ and particle sizes $(0.471-0.701 \mathrm{~mm}$ and 0.701-0.991 mm) of orange byproduct fibers did not affect composition, syneresis, color or sensory acceptance of fiber added yogurts (García-Pérez et al., 2005).

243 These previous examples indicate that it is possible to obtain dairy foods that are "source of fiber" and "high in dietary fiber" without compromising their sensory 245 acceptability. Future research should evaluate the satiating effect and gastrointestinal tolerance of a regular portion of the dairy products developed. As carbohydrates from

247 dietary fiber are non-digestible, they reach the large intestine, where they can be 248 fermented by colonic microbiota to different extents, depending on the degree of 249 polymerization, solubility and structure of the carbohydrates (Nyman, 2002). Therefore, consumption of high content dietary fiber products may cause potential secondary

251 effects from carbohydrate fermentation including bloating, distension, flatulence, loose 252 stools and increased stool frequency (Grabitske and Slavin, 2009). 


\section{Other ingredients}

254 Other innovations in dairy product development include the addition of ingredients

255 from animal origin byproducts: omega-3 fatty acids and proteins.

256 Fish oil can be extracted from fish wastes, and it is an excellent source of many

257 unsaturated fatty acids, including long chain n-3 cis-5,8,11,15,17- eicosapentaenoic acid

258 (EPA) and cis-4,7,10,13,16,19-docosahexaenoic acid (DHA) (Jayathilakan et al., 2012).

259 However, its application in food formulations is limited because of its easy oxidation and

260 strong odor (Zhong et al., 2018). Yogurts containing n-3 that had sensory attributes

261 similar to plain yogurt were obtained encapsulating fish oil in nano-liposomes

262 (Ghorbanzade et al., 2017), and adding a fish oil/ $/$-oryzanol nanoemulsion in yogurt

263 (Zhong et al., 2018).

264 Whey proteins obtained from cheese processing have been widely used as fat replacers

265 in dairy foods. Problems associated with using whey proteins and sodium caseinate as

266 fat replacers in yogurt included powdery taste, excessive acid development from lactose

267 fermentation, higher syneresis, excessive firmness and grainy texture (Sandoval-Castilla

268 et al., 2004). Recent studies have focused on improving texture in low fat yogurts and

269 low fat probiotic yogurts with added whey-buttermilk protein aggregates, whey protein

270 concentrate and heat-treated whey protein concentrates (Akalın et al., 2012; Saffon et

271 al., 2013; Zhang et al., 2015).

\section{Concluding remarks}

273 The large number of applications described in this chapter shows the high potential of

274 valorizing food byproducts for the development of novel dairy foods. This approach not 
275 only takes a step forward to waste reduction in the food chain, but also offers new ways

276 to diversify the production of dairy foods, launching the possibility of creating a market

277 niche based on functional and sustainable novel dairy foods. As many food byproducts

278 are sources of natural bioactive compounds and nutrients, their application could

279 reduce the use of synthetic ingredients without compromising the stability of the final

280 product, while fulfilling the current consumer demand towards using natural

281 ingredients. Dairy products with improved nutritional and health promoting properties,

282 as well as optimal sensory acceptance, can be achieved employing extracts from food

283 byproducts as novel food ingredients.

\section{Acknowledgments}

285 The authors would like to thank the projects FPLACT16 and SUSCOFFEE (AGL2014$28657239-R)$ for the financial support. The PhD grant of M. Iriondo-DeHond was funded by 287 IMIDRA.

\section{References}

289 Abid, Y., Azabou, S., Jridi, M., Khemakhem, I., Bouaziz, M. and Attia, H. (2017) 'Storage 290 stability of traditional Tunisian butter enriched with antioxidant extract from tomato

291 processing by-products', Food Chemistry. Elsevier Ltd, 233, pp. 476-482. doi: 10.1016/j.foodchem.2017.04.125.

Akalın, A. S., Unal, G., Dinkci, N. and Hayaloglu, A. A. (2012) 'Microstructural, textural, 294 and sensory characteristics of probiotic yogurts fortified with sodium calcium caseinate or whey protein concentrate', Journal of Dairy Science, 95(7), pp. 3617-3628. doi: 10.3168/jds.2011-5297. 
297 Aliakbarian, B., Casale, M., Paini, M., Casazza, A., Lanteri, S. and Perego, P. (2015)

298 'Production of a novel fermented milk fortified with natural antioxidants and its analysis

299 by NIR spectroscopy', Food Science \& Technology International, 62, pp. 376-383. doi: 300 dx.doi.org/10.1016/j.Itw.2014.07.037.

301 Álvarez, E. E. and González, P. (2006) 'La fibra dietética', Nutrición hospitalaria, 21, pp. $302 \quad 61-72$.

303 Ares, G., Giménez, A. and Deliza, R. (2010) 'Influence of three non-sensory factors on 304 consumer choice of functional yogurts over regular ones', Food Quality and Preference. Elsevier Ltd, 21(4), pp. 361-367. doi: 10.1016/j.foodqual.2009.09.002.

Bahadoran, Z., Mirmiran, P. and Azizi, F. (2013) 'Dietary polyphenols as potential 307 neutraceuticals in management of diabetes: a review', Journal of Diabetes \& Metabolic Disorders, 12, pp. 1-9. Available at: www.jdmdonline.com/content/12/1/43. and Zeppa, G. (2015) 'Influence of the addition of different hazelnut skins on the physicochemical, antioxidant, polyphenol and sensory properties of yogurt', LWT - Food

312 Science and Technology. Elsevier Ltd, 63(2), pp. 1145-1154. doi: 10.1016/j.Iwt.2015.03.113.

314 Chen, W., Duizer, L., Corredig, M. and Goff, H. D. (2010) 'Addition of soluble soybean 315 polysaccharides to dairy products as a source of dietary fiber', Journal of Food Science, 316 75(6), pp. 478-484. doi: 10.1111/j.1750-3841.2010.01688.x.

317 Chouchouli, V., Kalogeropoulos, N., Konteles, S. J., Karvela, E., Makris, D. P. and 318 Karathanos, V. T. (2013) 'Fortification of yoghurts with grape (Vitis vinifera) seed 
extracts', LWT - Food Science and Technology. Elsevier Ltd, 53(2), pp. 522-529. doi: 10.1016/j.Iwt.2013.03.008.

321 Costa, C., Tsatsakis, A., Mamoulakis, C., Teodoro, M., Briguglio, G., Caruso, E., Tsoukalas, 322 D., Margina, D., Dardiotis, E., Kouretas, D. and Fenga, C. (2017) 'Current evidence on the 323 effect of dietary polyphenols intake on chronic diseases', Food and Chemical Toxicology. 324 Elsevier, 110(August), pp. 286-299. doi: 10.1016/j.fct.2017.10.023.

325 Crizel, T. de M., Araujo, R. R. de, Rios, A. de O., Rech, R. and Flôres, S. H. (2014) ‘Orange 326 fiber as a novel fat replacer in lemon ice cream', Food Science and Technology 327 (Campinas), 34(2), pp. 332-340. doi: 10.1590/fst.2014.0057.

328 Çam, M., Erdoğan, F., Aslan, D. and Dinç, M. (2013) ‘Enrichment of Functional Properties 329 of Ice Cream with Pomegranate By-products', Journal of Food Science, 78(10), pp. 1543330 1550. doi: $10.1111 / 1750-3841.12258$.

331 Demirci, T., Aktaş, K., Sözeri, D., Öztürk, H. İ. and Akın, N. (2017) 'Rice bran improve 332 probiotic viability in yoghurt and provide added antioxidative benefits', Journal of 333 Functional Foods, 36, pp. 396-403. doi: 10.1016/j.jff.2017.07.019.

334 Dimitrios, B. (2006) 'Sources of natural phenolic antioxidants', Trends in Food Science 335 and Technology, 17(9), pp. 505-512. doi: 10.1016/j.tifs.2006.04.004.

336 El-Said, M. M., Haggag, H. F., Fakhr El-Din, H. M., Gad, A. S. and Farahat, A. M. (2014) 337 'Antioxidant activities and physical properties of stirred yoghurt fortified with 338 pomegranate peel extracts', Annals of Agricultural Sciences. Faculty of Agriculture, Ain 339 Shams University, 59(2), pp. 207-212. doi: 10.1016/j.aoas.2014.11.007.

340 Ersöz, E., Kınık, Ö., Yerlikaya, O. and Açu, M. (2011) 'Effect of phenolic compounds on 
341 characteristics of strained yoghurts produced from sheep milk', 6(23), pp. 5351-5359.

342 doi: 10.5897/AJAR11.1012.

343 do Espírito Santo, A. P., Cartolano, N. S., Silva, T. F., Soares, F. A. S. M., Gioielli, L. A.,

344 Perego, P., Converti, A. and Oliveira, M. N. (2012) 'Fibers from fruit by-products enhance 345 probiotic viability and fatty acid profile and increase CLA content in yoghurts', 346 International Journal of Food Microbiology. Elsevier B.V., 154(3), pp. 135-144. doi: 347 10.1016/j.ijfoodmicro.2011.12.025.

348 European Food Safety Authority (2010) 'Scientific Opinion on Dietary Reference Values 349 for carbohydrates and', EFSA Journal, 8(3), pp. 1-77. doi: $350 \quad$ 10.2903/j.efsa.2010.1462.Available.

351 European Parliament and Council (2006) Regulation (EC) No 1924/2006 on nutrition and 352 health claims made on foods.

353 FAO (2017) FAOSTAT. Available at: http://www.fao.org/faostat (Accessed: 18 December 354 2017).

355 FAO (2011) Global food losses and food waste - Extent, causes and prevention., SAVE 356 FOOD: An initiative on Food Loss and Waste Reduction. doi: 10.1098/rstb.2010.0126.

357 Food and Drug Administration (2018), Nutrition \& supplement facts label proposed 358 rule. Available at:

359 http://www.fda.gov/downloads/Food/NewsEvents/WorkshopsMeetingsConferences/ $360 \quad$ UCM403514.pdf

361 Felix da Silva, D., Matumoto-Pintro, P. T., Bazinet, L., Couillard, C. and Britten, M. (2015) 362 'Effect of commercial grape extracts on the cheese-making properties of milk', Journal 
364 Frumento, D., Santo, A. P. do E., Aliakbarian, B., Casazza, A. A., Gallo, M., Converti, A. 365 and Perego, P. (2013) 'Development of milk fermented with Lactobacillus acidophilus 366 fortified with Vitis vinifera marc flour', Food Technology and Biotechnology, 51(3), pp. $367 \quad 370-375$.

368 Galanakis, C. M. (2011) 'Olive fruit dietary fiber: Components, recovery and 369 applications', Trends in Food Science and Technology. Elsevier Ltd, 22(4), pp. 175-184. 370 doi: 10.1016/j.tifs.2010.12.006.

371 García-Pérez, F. J., Lario, Y., Fernández-López, J., Sayas, E., Pérez-Alvarez, J. A. and 372 Sendra, E. (2005) 'Effect of orange fiber addition on yogurt color during fermentation 373 and cold storage', Color Research and Application, 30(6), pp. 457-463. doi: $374 \quad 10.1002 /$ col.20158.

375 Ghorbanzade, T., Jafari, S. M., Akhavan, S. and Hadavi, R. (2017) 'Nano-encapsulation of 376 fish oil in nano-liposomes and its application in fortification of yogurt', Food Chemistry. 377 Elsevier Ltd, 216, pp. 146-152. doi: 10.1016/j.foodchem.2016.08.022.

378 Göksel Saraç, M. and Dogan, M. (2016) 'Incorporation of dietary fiber concentrates from 379 fruit and vegetable wastes in butter: effects on physicochemical, textural, and sensory 380 properties', European Food Research and Technology. Springer Berlin Heidelberg, 381 242(8), pp. 1331-1342. doi: 10.1007/s00217-016-2637-9.

382 Grabitske, H. A. and Slavin, J. L. (2009) 'Gastrointestinal effects of low-digestible 383 carbohydrates', Critical Reviews in Food Science and Nutrition, 49(4), pp. 327-360. doi: 10.1080/10408390802067126. 
385 Granato, D., Branco, G. F., Cruz, A. G., Faria, J. de A. F. and Shah, N. P. (2010) 'Probiotic 386 dairy products as functional foods', Comprehensive Reviews in Food Science and Food 387 Safety, 9(5), pp. 455-470. doi: 10.1111/j.1541-4337.2010.00120.x.

388 Granato, D., de Castro, I. A., Ellendersen, L. S. N. and Masson, M. L. (2010) ‘Physical 389 stability assessment and sensory optimization of a dairy-free emulsion using response 390 surface methodology', Journal of Food Science, 75(3), pp. 149-155. doi: 10.1111/j.1750$391 \quad 3841.2010 .01514 . x$.

392 Guillon, F. and Champ, M. (2000) 'Structural and physical properties of dietary fibres, 393 and consequences of processing on human physiology', Food Research International, 394 33(3-4), pp. 233-245. doi: 10.1016/S0963-9969(00)00038-7.

395 Hashim, I. B., Khalil, A. H. and Afifi, H. S. (2009) 'Quality characteristics and consumer 396 acceptance of yogurt fortified with date fiber.', Journal of dairy science. Elsevier, 92(11), 397 pp. 5403-7. doi: 10.3168/jds.2009-2234.

398 Haslam, E. and Lilley, T. H. (1988) 'Natural astringency in foodstuffs - A molecular 399 interpretation', Critical Reviews in Food Science and Nutrition Natural, (August 2011), 400 pp. 37-41.

401 Issar, K., Sharma, P. C. and Gupta, A. (2016) 'Utilization of Apple Pomace in the 402 Preparation of Fiber-Enriched Acidophilus Yoghurt', Journal of Food Processing and 403 Preservation, 0, pp. 1-6. doi: 10.1111/jfpp.13098.

404 Jayathilakan, K., Sultana, K., Radhakrishna, K. and Bawa, A. S. (2012) 'Utilization of 405 byproducts and waste materials from meat, poultry and fish processing industries: A 406 review', Journal of Food Science and Technology, 49(3), pp. 278-293. doi: 
408 Jridi, M., Souissi, N., Salem, M. Ben, Ayadi, M. A., Nasri, M. and Azabou, S. (2015)

409 'Tunisian date (Phoenix dactylifera L.) by-products: Characterization and potential 410 effects on sensory, textural and antioxidant properties of dairy desserts', Food 411 Chemistry. Elsevier Ltd, 188, pp. 8-15. doi: 10.1016/j.foodchem.2015.04.107.

412 Karnopp, A. R., Oliveira, K. G., de Andrade, E. F., Postingher, B. M. and Granato, D. (2017)

413 'Optimization of an organic yogurt based on sensorial, nutritional, and functional 414 perspectives', Food Chemistry. Elsevier Ltd, 233, pp. 401-411. doi: $415 \quad$ 10.1016/j.foodchem.2017.04.112.

416 Kaur, D., Wani, A. A., Singh, D. P. and Sogi, D. S. (2011) 'Shelf Life Enhancement of Butter, 417 Ice-Cream, and Mayonnaise by Addition of Lycopene', International Journal of Food 418 Properties, 14(6), pp. 1217-1231. doi: 10.1080/10942911003637335.

419 Lindström, J., Peltonen, M., Eriksson, J. G., Louheranta, A., Fogelholm, M., Uusitupa, M. 420 and Tuomilehto, J. (2006) 'High-fibre, low-fat diet predicts long-term weight loss and 421 decreased type 2 diabetes risk: The Finnish Diabetes Prevention Study', Diabetologia, 422 49(5), pp. 912-920. doi: 10.1007/s00125-006-0198-3.

423 Marchiani, R., Bertolino, M., Belviso, S., Giordano, M., Ghirardello, D., Torri, L., Piochi, 424 M. and Zeppa, G. (2016) 'Yogurt enrichment with grape pomace: effect of grape cultivar 425 on physicochemical, microbiological and sensory properties', Journal of Food Quality, 426 39(2), pp. 77-89. doi: 10.1017/CBO9781107415324.004.

427 Marchiani, R., Bertolino, M., Ghirardello, D., McSweeney, P. L. H. and Zeppa, G. (2015) 428 'Physicochemical and nutritional qualities of grape pomace powder-fortified semi-hard 
429 cheeses', Journal of Food Science and Technology. Journal of Food Science and 430 Technology, 53(3), pp. 1585-1596. doi: 10.1007/s13197-015-2105-8.

431 McKee, L. H. and Latner, T. A. (2000) 'Underutilized sources of dietary fiber: A review', 432 Plant Foods for Human Nutrition, 55(4), pp. 285-304. doi: 10.1023/A:1008144310986.

433 Menrad, K. (2003) 'Market and marketing of functional food in Europe', Journal of Food 434 Engineering, 56(2-3), pp. 181-188. doi: 10.1016/S0260-8774(02)00247-9. Chromatography A, 1054(1-2), pp. 95-111. doi: 10.1016/j.chroma.2004.08.059. Oxidative Stability of Whey Butter through Almond (Prunus dulcis) Peel Extract', Journal of Food Processing and Preservation, 39(6), pp. 591-598. doi: 10.1111/jfpp.12265. case of inulin and oligofructose', British Journal of Nutrition, 87(S2), p. S163. doi: 10.1079/BJN/2002533.

443 Ozcan, T., Yilmaz-Ersan, L., Akpinar-Bayizit, A. and Delikanli, B. (2016) 'Antioxidant 444 properties of probiotic fermented milk supplemented with chestnut flour ( $C$ astanea 445 sativa Mill)', Journal of Food Processing and Preservation, (June). doi: $446 \quad 10.1111 /$ jfpp.13156.

447 Pasotti, L., Zucca, S., Casanova, M., Micoli, G., Cusella De Angelis, M. G. and Magni, P. 448 (2017) 'Fermentation of lactose to ethanol in cheese whey permeate and concentrated 449 permeate by engineered Escherichia coli', BMC Biotechnology. BMC Biotechnology, 17(1), pp. 1-12. doi: 10.1186/s12896-017-0369-y. 
451 Pereira, M., O’Reilly, E., Augustsson, K., Fraser, G., Goldbourt, U., Heitmann, B., 452 Hallmans, G., Knekt, P., Liu, S., Pietinen, P., Spiegelman, D., Stevens, J., Virtamo, J., 453 Willet, W. and Ascherio, A. (2004) 'Dietary Fiber and Risk of Coronary Heart Disease', 454 Archives of Internal Medicine, 164, pp. 370-376. doi: 455 10.1097/01.ieb.0000142783.97667.b5.

456 Pérez-Jiménez, J., Neveu, V., Vos, F. and Scalbert, A. (2010) 'Identification of the 100 457 richest dietary sources of polyphenols: An application of the Phenol-Explorer database', 458 European Journal of Clinical Nutrition, 64, pp. S112-S120. doi: 10.1038/ejcn.2010.221.

459 Perina, N. P., Granato, D., Hirota, C., Cruz, A. G., Bogsan, C. S. B. and Oliveira, M. N. (2015) 460 'Effect of vegetal-oil emulsion and passion fruit peel-powder on sensory acceptance of 461 functional yogurt', Food Research International. Elsevier Ltd, 70, pp. 134-141. doi: $462 \quad$ 10.1016/j.foodres.2015.01.014.

463 Peters, U., Sinha, R., Chatterjee, N., Subar, A. F., Ziegler, R. G., Kulldorff, M., Bresalier, R., 464 Weissfeld, J. L., Flood, A., Schatzkin, A. and Hayes, R. B. (2003) 'Dietary fibre and 465 colorectal adenoma in a colorectal cancer early detection programme', Lancet, 466 361(9368), pp. 1491-1495. doi: 10.1016/S0140-6736(03)13173-X.

467 Rizk, E. M., El-Kady, A. T. and El-Bialy, A. R. (2014) ‘Charactrization of carotenoids (lyco468 red) extracted from tomato peels and its uses as natural colorants and antioxidants of 469 ice cream', Annals of Agricultural Sciences. Faculty of Agriculture, Ain Shams University, $470 \quad$ 59(1), pp. 53-61. doi: 10.1016/j.aoas.2014.06.008.

471 Saffon, M., Richard, V., Jiménez-Flores, R., Gauthier, S., Britten, M. and Pouliot, Y. (2013) 472 'Behavior of Heat-Denatured Whey:Buttermilk Protein Aggregates during the Yogurt- 
473 Making Process and Their Influence on Set-Type Yogurt Properties', Foods, 2(4), pp. 444474 459. doi: $10.3390 /$ foods 2040444.

475 Sah, B. N. P., Vasiljevic, T., McKechnie, S. and Donkor, O. N. (2016) 'Physicochemical, 476 textural and rheological properties of probiotic yogurt fortified with fibre-rich pineapple 477 peel powder during refrigerated storage', LWT-Food Science and Technology. Elsevier 478 Ltd, 65, pp. 978-986. doi: 10.1016/j.Iwt.2015.09.027.

479 Sandoval-Castilla, O., Lobato-Calleros, C., Aguirre-Mandujano, E. and Vernon-Carter, E. 480 J. (2004) 'Microstructure and texture of yogurt as influenced by fat replacers', 481 International Dairy Journal, 14(2), pp. 151-159. doi: 10.1016/S0958-6946(03)00166-3.

482 dos Santos, K. M. O., de Oliveira, I. C., Lopes, M. A. C., Cruz, A. P. G., Buriti, F. C. A. and 483 Cabral, L. M. (2017) 'Addition of grape pomace extract to probiotic fermented goat milk: 484 the effect on phenolic content, probiotic viability and sensory acceptability', Journal of 485 the Science of Food and Agriculture, 97(4), pp. 1108-1115. doi: 10.1002/jsfa.7836.

486 Scalbert, A., Manach, C., Morand, C., Rémésy, C. and Jiménez, L. (2005) 'Dietary 487 polyphenols and the prevention of diseases', Critical Reviews in Food Science and 488 Nutrition, 45(4), pp. 287-306. doi: 10.1080/1040869059096.

489 Sendra, E., Kuri, V., Fernández-López, J., Sayas-Barberá, E., Navarro, C. and Pérez490 Alvarez, J. A. (2010) 'Viscoelastic properties of orange fiber enriched yogurt as a function 491 of fiber dose, size and thermal treatment', LWT - Food Science and Technology, 43(4), 492 pp. 708-714. doi: 10.1016/j.Iwt.2009.12.005. Shahidi, F. and Naczk, M. (2006) Phenolics in food and nutraceuticals, New York. doi: 1- 

herb extracts as natural preservatives in cheese.', Journal of medicinal food, 14(3), pp. 284-90. doi: 10.1089/jmf.2010.0009.

'Utilization of food processing by-products as dietary, functional, and novel fiber: A

500 review', Critical Reviews in Food Science and Nutrition, 56(10), pp. 1647-1661. doi:

Teixeira, A., Baenas, N., Dominguez-Perles, R., Barros, A., Rosa, E., Moreno, D. A. and Garcia-Viguera, C. (2014) 'Natural bioactive compounds from winery by-products as health promoters: A review', International Journal of Molecular Sciences, 15(9), pp. 15638-15678. doi: 10.3390/ijms150915638.

Tseng, A. and Zhao, Y. (2013) 'Wine grape pomace as antioxidant dietary fibre for enhancing nutritional value and improving storability of yogurt and salad dressing', Food Chemistry. Elsevier Ltd, 138(1), pp. 356-365. doi: 10.1016/j.foodchem.2012.09.148.

Urala, N. and Lähteenmäki, L. (2007) ‘Consumers' changing attitudes towards functional

510 foods', Food Quality and Preference, 18(1), pp. 1-12. doi: 10.1016/j.foodqual.2005.06.007.

513 of addition of Agaricus blazei mushroom residue to milk enriched with Omega-3 on the prevention of lipid oxidation and bioavailability of bioactive compounds after in vitro gastrointestinal digestion', International Journal of Food Science \& Technology, 52(6), pp. 1483-1490. doi: 10.1111/ijfs.13413. 
517 Yi, T., Huang, X., Pan, S. and Wang, L. (2014) 'Physicochemical and functional properties

518 of micronized jincheng orange by-products (Citrus sinensis Osbeck) dietary fiber and its

519 application as a fat replacer in yogurt', International journal of food ..., 86(5), pp. 565-

$520 \quad$ 572. doi: $10.3109 / 09637486.2014 .898252$.

521 Zhang, T., Mccarthy, J., Wang, G., Liu, Y. and Guo, M. (2015) 'Physiochemical Properties,

522 Microstructure, and Probiotic Survivability of Nonfat Goats' Milk Yogurt Using Heat-

523 Treated Whey Protein Concentrate as Fat Replacer', Journal of Food Science, 80(4), pp.

524 M788-M794. doi: 10.1111/1750-3841.12834.

525 Zhong, J., Yang, R., Cao, X., Liu, X. and Qin, X. (2018) 'Improved Physicochemical

526 Properties of Yogurt Fortified with Fish Oil/Y-Oryzanol by Nanoemulsion Technology',

527 Molecules, 23(1), p. 56. doi: 10.3390/molecules23010056.

528

529 